fundamentales de estas enfermedades colectivas: por un lado, el enorme sufrimiento humano y la sensación de caos que acarrea una epidemia; por el otro, la influencia de la desigualdad o la veleidad política en la magnitud de sus repercusiones.

Por un lado, ya corresponda a pestes de la Edad Media o del siglo xx, ya sea en Europa, América, África o Medio Oriente, las descripciones de los estragos de las epidemias, sean de peste bubónica, lepra, viruela, cólera o fiebre amarilla resultan estrujantemente familiares. Igualmente, resultan familiares las luchas de poder, las tensiones entre la clerecía burocrática, médica y religiosa, el inevitable choque entre las prescripciones higiénicas y las creencias populares (las frecuentes escenas en las que los habitantes sublevados en las ciudades europeas hurtaban los cadáveres de las fosas comunes y los llevaban a enterrar a sus Iglesias) y las reacciones extremas de sociedades aterradas, en busca de exorcistas y chivos expiatorios. Por lo demás, si bien todas las epidemias producen muertes, mutilaciones y deformaciones físicas, también gradúan su dolor de distintos modos. Por ejemplo, una misma desgracia se experimenta de diversa manera y no es lo mismo el contagio azaroso y la muerte fulminante por peste bubónica, cólera o fiebre amarilla, que las muertes lentas y estigmatizantes de las víctimas de esas epidemias lentas e insidiosas de la lepra o la sífilis que asolaron el mundo por siglos.

Igualmente, si bien es cierto que las epidemias son en cierto modo "democráticas", los pobres invariablemente tienden a ser más vulnerables y a sufrir las peores secuelas. La disposición de mayores posibilidades y espacios para aislarse, para mantener la higiene o para tener acceso a tratamientos médicos y asistencia personal de los más ricos y poderosos o, incluso, las normas asimétricas en su favor, han exacerbado históricamente el efecto distintivo de la enfermedad sobre los más pobres. Con todo, las epidemias no siempre apuntalan el status quo y, en ocasiones, han sido protagonistas invisibles de la política interna de las naciones o de la geopolítica, provocando revueltas repentinas o, de manera más lenta, influyendo en la demografía y la economía. Muchos ambiciosos gobernantes, o naciones en ascenso, vieron frustrados sus afanes y terminaron en el sótano de la historia, debido al efecto de alguna epidemia.

El recuento de calamidades de Watts ilustra, también, que las epidemias implican estados de excepción que anulan los eventuales contrapesos sociales, concentran el poder y magnifican el margen de maniobra de las élites. Así, la templanza o la megalomanía, la virtud o la estulticia, de quienes conducen las crisis sanitarias resultan determinantes $\mathrm{y}$, con las oscilaciones y transfiguraciones emocionales de unos cuantos, la suerte juega sus dados con los humanos.

\section{Dos visiones de una misma peste}

El abordaje de las epidemias en la literatura ofrece un amplio mosaico de las actitudes morales, las respuestas políticas y las variantes emocionales ante esta calamidad. Por ejemplo, la incredulidad e irresponsabilidad de los tiranos ante la enfermedad (Napoleón negaba la fiebre amarilla, que frenó sus campañas en América, y la consideraba una "ofensa personal"); la histeria, la superstición y estigmatización (el mago Apolonio que lapidaba mendigos para salvar a Efeso de la peste) o la codicia de los que hacen negocio con la desgracia (el deslumbrante y repugnante Samuel Pepys que dice en sus Diarios: "Nunca he vivido tan dichosamente, ni gané tanto dinero, como en esta época de la peste"). ${ }^{1}$

En efecto, durante la peste de Londres de 1665 , Samuel Pepys (1633-1703), el muchacho desposeído que gracias a su esfuerzo y astucia llegó a ser un rico funcionario y hombre de mundo, que dejó

1 "I have never lived so merrily (besides that I never got so much) as I have done this plague time". 
como testamento histórico y literario sus Diarios, bebió, comió, amó e hizo más negocios que nunca. En su diario, Pepys registra que la peste se anuncia en abril, con vagas noticias que parecen fantasía. Poco después, en uno de sus paseos por la ciudad Pepys observa dos casas señaladas con una cruz roja y el letrero "Dios se apiade de nosotros" y es tal su miedo que tiene que mascar tabaco para mantener el equilibrio. Con todo, Pepys sigue sus ocupaciones mundanas (las labores de funcionario del almirantazgo, las intrigas y alcahueteos de alta sociedad) y los cientos de muertes cotidianas son, en sus Diarios, sólo apuntes incidentales, ráfagas de preocupación sobre la volubilidad de la fortuna. Con el tiempo, sin embargo, el tema gana importancia: ya no sólo mueren plebeyos sino conocidos, hay casas clausuradas cada vez más cerca de su exclusivo domicilio y cierran los comercios, lupanares y tabernas que frecuentaba.

Pepys se muda a un lugar más seguro; aburrido por la mengua de actividades, se hace divertir por sus criadas, visita a sus múltiples amantes y consigna que se acostó con ellas con una frase que supone indescifrable para su aguerrida esposa: "Faciebam le cose que ego tenebam a mind to con elle". ${ }^{2}$ La vida social no se suspende del todo, pero tiene inconvenientes y es frecuente que, al regreso de sus compromisos, Pepys tropiece con los cadáveres de apestados. Conforme el tiempo pasa, las disposiciones sanitarias se hacen más rígidas, las familias confinadas reciben una virtual condena a muerte, todos desconfían de todos, a la ciudad fantasmal sólo la surcan turbas de menesterosos agobiados por el hambre. Por lo demás, las prohibiciones civiles y las prescripciones higiénicas chocan con el culto y el sentimiento de los londinenses: los ciudadanos rehúsan prescindir de las procesiones funerales y algunos hombres, piadosos o locos, rescatan a niños sanos, condenados a

2 Pepys, The Diary of Samuel Pepys Daily entries from the 17th century London diary. https://www.pepysdiary.com/diary morir con sus familias apestadas. Tras meses interminables, han muerto miles y aún se escuchan rumores de rebrotes, pero el helado invierno tiende a disipar la pesadilla. Pepys da gracias a Dios porque, en el curso de la peste, no ha perdido su sagacidad para los negocios, ni el buen humor, ni esa forma de ilusión que es la frivolidad; pero no todo son buenas noticias, el fin de la plaga le trae nuevas preocupaciones: "Día del Señor. Me puse el traje de color, que tiene gran prestancia y mi peluca nueva, que no me atrevía a usar porque la peste arreciaba en Westminster cuando la compré. Quisiera saber si las pelucas estarán todavía de moda cuando la epidemia termine: nadie osará comprar cabello con el temor de que pertenezca a cadáveres apestados". 3

Por su parte, El diario del año de la peste de Daniel Defoe (1660-1731), apoyado en documentos y estadísticas oficiales y en distintos testimonios de supervivientes, reconstruye narrativamente, con precisión y fuerza alegórica, esa misma epidemia de fiebre bubónica que vivió de muy niño. En 1665 la peste se extiende en Londres, todos los que tienen dinero inician un éxodo al campo con sus familias y sus sirvientes, el narrador, un acomodado comerciante de talabartería, duda en abandonar la ciudad, pues teme por la seguridad de sus posesiones y, además, tiene un vago sentido de solidaridad cívica. Irresoluto, decide consultar la Biblia al azar y encuentra un versículo en el que interpreta que Dios lo protege, lo que lo convence de quedarse. Poco a poco, a su barrio afluente lo rodea la peste, que primero se había ensañado con los arrabales. Tras las laceraciones de las primeras muertes, y ante la profusión de la mortandad, el llanto sale sobrando y sólo se instala una sorda tristeza y desolación en la ciudad. La extrema incertidumbre hace que muchos se refugien en la religión y otros en las supersticiones, profecías y amuletos. También proliferan médicos impostores y curanderos improvisa-

\footnotetext{
3 Pepys, Diarios 166o-1669, 360.
} 
dos que esquilman a los pobres con pócimas falsas. Las medidas de la autoridad son drásticas: las casas donde habitan infectados se marcan visiblemente y se clausuran con todo y sus habitantes; se suspenden las pompas funerales; se decreta el sacrificio de todos los perros y gatos (aunque ello limita las defensas contra las ratas) y se cavan inmensas fosas para arrojar a los muertos, a las que muchos infectados acuden delirantes a enterrarse vivos. Cierto, no faltan aquellos que, mientras permanecen abiertas las tabernas, se reúnen para blasfemar y mofarse de los demás. Sin embargo, a medida que la epidemia arrecia, la convivencia se descompone hasta el terror, muchos padres abandonan a sus hijos o viceversa y se sospecha que los cuidadores abrevian violentamente la vida de los contagiados. En la época más álgida de la epidemia, ya no es fácil salir de Londres, pues los habitantes del campo rechazan a los citadinos. Muchos pobres que huyen de la ciudad mueren, más que de la peste, de miedo o inanición; otros viven en la campiña como ermitaños o en pequeños grupos $\mathrm{y}$, como Robinson Crusoe, tienen que hacer acopio de todo su ingenio civilizatorio para sobrevivir. Cuando el desastre se vuelve inaudito, se produce un relajamiento funeral: todos se saben cadáveres y, apabullados sus egos, una mansa sociabilidad los inunda. El invierno se apiada de estos fantasmas y desvanece la enfermedad, un año después, el gran incendio de Londres, terminará de purificar los miasmas de la epidemia.

A partir de un mismo episodio histórico, pueden verse dos actitudes totalmente distintas: el diario de Pepys es un muestrario de descarnada picardía y pragmatismo que, a la vez que expresa un enorme miedo a la pandemia, muestra un extremado ingenio para continuar divirtiéndose y obtener ganancias monetarias sin que haya, en ningún momento, un sentimiento de identificación o empatía con el sufrimiento de los demás. En contraste, el narrador de Defoe, sin incurrir en actos heroicos, muestra su azoro y preocupación por el fenómeno de contagio y sus devastadores efectos sociales, observa los comporta-

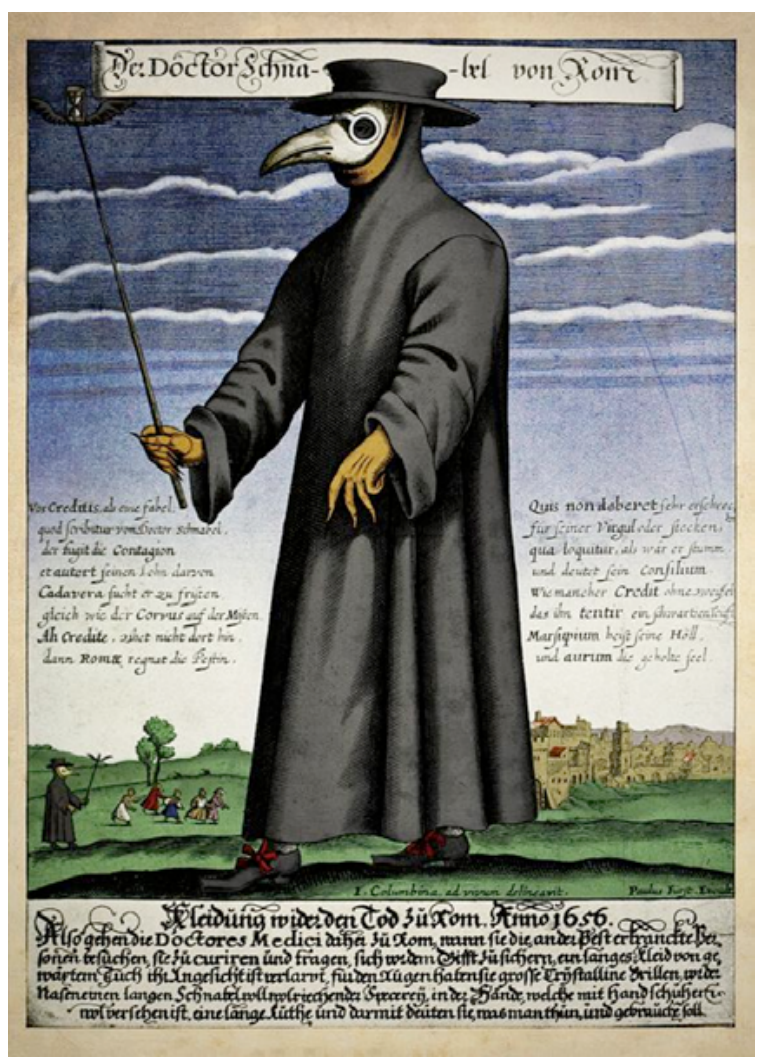

Grabado en color del Doctor Schnabel [Dr. Beak], un médico en la peste en Roma, publicado por Paul Fürst, ca. 1656.

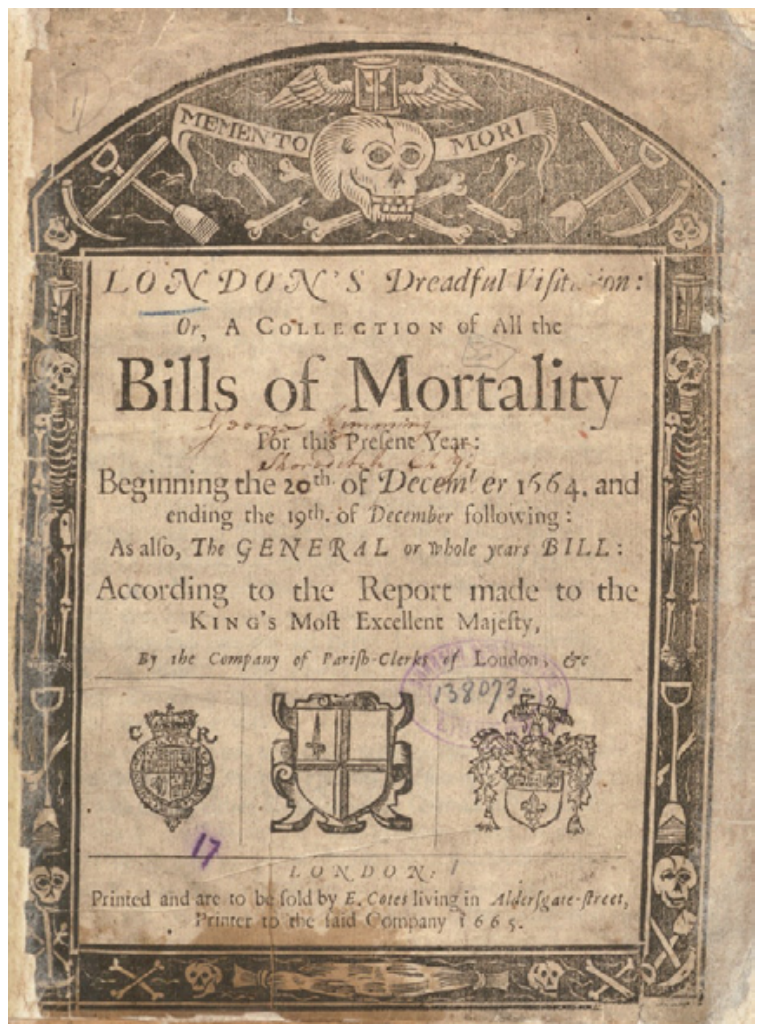

Portada de London's Dreadful Visitation: Or, A Collection of All the Bills of Mortality for this Present Year. 
mientos de diversos actores y, pese a su imposibilidad de actuar, manifiesta una solidaridad con el sufrimiento ajeno. Desde luego, no cabe necesariamente inferir categorías morales en los escritores: la narración de Pepys constituye un testimonio de primera mano, y está situada en el centro del horror, y acaso dictada por el más apremiante temor, sentido de novedad e instinto de supervivencia. Por su parte, Defoe contempla el hecho desde una perspectiva histórica, que puede evaluar en retrospectiva la magnitud del horror de la epidemia y, por supuesto, también desde su acendrado espíritu religioso. Se trata, asimismo, de dos géneros novedosos y desconcertantes: los diarios de Pepys, un extraordinario documento histórico y literario que, sin embargo, parece carecer de cualquier pretensión literaria o ambición de posteridad y la novela de Defoe, que, acudiendo a la investigación histórica y periodística tanto como a la ficción, juega con el tono del testimonio.

\section{La catástrofe insolidaria}

En las epidemias, como en otras situaciones límite, las reacciones pueden ser muy diversas y responden a la historia y carácter personal de los individuos. Sin embargo, muy probablemente la amenaza sanitaria, por su naturaleza peculiar, acaso tiende a uniformar las respuestas, exacerbar el sentimiento de aislamiento y los miedos anti-sociales. Dice Rebeca Solnit en su libro A Paradise Built in Hell que si bien las catástrofes (terremotos, huracanes, incendios, accidentes industriales) generan impactos devastadores, también despiertan sentimientos y actitudes de solidaridad, altruismo y organización espontánea, narcotizados en la vida moderna. Conjeturo, sin embargo, que las epidemias constituyen las menos empáticas de las catástrofes y su influjo tiende a aislar a los individuos y a resaltar sus peores rasgos, sus más acendrados prejuicios y sus más profundos temores. Ya lo sugería Elías Canetti en Masa y poder, a diferen- cia de, por ejemplo, un terremoto que cobra el grueso de sus víctimas de una vez, la epidemia es una catástrofe que se despliega gradual y acumulativamente. Si en la catástrofe súbita la naturaleza propina un nocaut a la soberbia humana, la catástrofe epidémica es una acechanza calculada que perpetua el miedo. Si en la catástrofe fulminante el superviviente puede ejercer su condolencia con los muertos y con las otras víctimas, en la catástrofe gradual, el superviviente sospecha de los demás como foco de infección y tiende a poner a la enfermedad su rostro más temido u odiado: el del extranjero, el del adversario o el del desposeído. Por eso, la epidemia constituye una calamidad en cámara lenta que gotea con ácido los vínculos comunitarios y se configura en la imaginación social como un contendiente mortal y ubicuo que se puede ocultar en el abrazo de los prójimos más próximos. Como dice Canetti: "El contagio, tan importante en la epidemia, hace que los hombres se aparten unos de otros. Lo más seguro es no acercarse demasiado a nadie, pues podría acarrear el contagio. Algunos huyen de la ciudad y se dispersan en sus posesiones. Otros se encierran en sus casas y no admiten a nadie. Los unos evitan a los otros. El mantener las distancias se convierte en última esperanza". ${ }^{4}$

Referencias

Canetti, Elías. Masa y poder. Madrid: Alianza-Muchnik, 1983.

Defoe, Daniel. Diario del año de la peste. Madrid: Impedimenta, 2010.

Pepys, Samuel. Diarios 166o-1669. Sevilla: Renacimiento, 2014 .

_. The Diary of Samuel Pepys Daily entries from the 17th century London diary. https://www.pepysdiary. com/diary

Solnit, Rebeca. A Paradise Built in Hell. Nueva York: Penguin, 2010.

Watts, Sheldon. Epidemias y poder. Historia, enfermedad, imperialismo. Santiago: Andrés Bello, 2000.

4 Canetti, Masa y poder, 269-270. 